\title{
CONSISTENCY IN REMOTE SENSING-BASED URBAN MAPPING FOR GROWTH AND MOBILITY ANALYSIS
}

\author{
L. Møller-Jensen ${ }^{1, *}$, A. N. Allotey ${ }^{2}$ \\ ${ }^{1}$ Dept. of Geosciences and Natural Resource Management, University of Copenhagen, \\ Oster Voldgade 10, 1350, Copenhagen, Denmark - lmj@ geo.ku.dk \\ ${ }^{2}$ Institute for Scientific and Technological Information, Council for Scientific \& Industrial Research, \\ Augustino Neto Road, Accra, Ghana - allotey2@gmail.com
}

KEY WORDS: urban mapping, remote sensing, mobility, transport, climate change

\begin{abstract}
:
This extended abstract presents initial results from a study that focus on the accuracy of satellite-based maps of Accra's urban expansion as well as their comparability and ability to provide a basis for assessing urban spatial growth dynamics. Within the study we have analysed five different satellite-derived maps of urban development in Accra and compared the results and underlying methods. It is discussed how these maps can be operationalized and, combined with census data and digital road maps, used for calculating how flood events that disable parts of the transport infrastructure impact the overall mobility of the Accra population.
\end{abstract}

\section{BACKGROUND}

This current study is part of a project that aims to identify research-based strategies for increasing climate change resilience within urban mobility, accessibility and transport in Accra, Ghana. Climate change induced mobility-constraints have a number of consequences, including reducing access to work, limiting the number of accessible jobs, and constraining access to services. Mobility and accessibility in Accra is challenged by severe congestion in many areas, insufficient road capacity and poor road conditions.

Frequent flooding severely affects and hampers mobility by disabling parts of the transport network thereby contributing to the pervasive and exacerbating accessibility problems. This situation is worsened by the fact that there is very little redundancy in the high-level transport network of Accra. A major goal of the project is to calculate the flood probability for different locations in the urban areas, as well as the impact of such flooding in terms of reduction in overall mobility for the population.

A number of spatial data sets are required for producing risk maps that combines the flood probability values with computed flood impact estimates, (e.g. in terms of loss of mobility), such as maps of the urban area, the transport network and the population distribution. The focus of the current, on-going, study is to obtain credible estimates of the urban extent, population distribution and expected future growth.

\section{METHODOLOGY}

The following data sets were acquired and analysed: 1) Urban expansion (1985-2002) using texture-based analysis of LandsatTM images (Møller-Jensen et al., 2005), 2) Global Urban Footprint (2012) using SAR imagery from the TanDEM-X mission (Esch et al, 2013, DLR, 2019), 3) Atlas of Urban Expansion (1991-2014) based on Landsat-TM images (Angel et al., 2016), 4) Africapolis (2015) based on various sources (Africapolis, 2019) and 5) a new dataset for 2017 prepared by the authors based on segmented Sentinel-2 data combined with high-resolution Google Earth imagery.

The main purpose of the latter dataset is to provide additional data on the degree of urbanization in the fringe areas of the Accra agglomeration. Area and urban extension estimates for the Accra agglomeration were computed from each dataset, and metadata was analysed in order to assess the classification methodology underlying each map and the corresponding implicit or explicit definitions of what constitutes an urban area.

\section{FINDINGS}

A central finding is that comparisons between different satellitederived maps of urban areas may be difficult and potentially misleading, since the urban categories are operationalized differently and often without explicit definitions. Two different types of remote sensing approaches were identified: The method behind the Global Urban Footprint dataset aims to identify exclusively areas with man-made, impervious surfaces such as roads and buildings as proxies for urban extent.

The methods behind the rest of the datasets were more 'inclusive' aiming to identify a broader set of land cover types, including parks and open spaces, that are considered a part of the mixed urban fabric. Further differences were found in the way urban fringe areas under development are classified depending on their degree of urbanization as well as the applied distance threshold values for including/excluding sites into the urban agglomeration. 


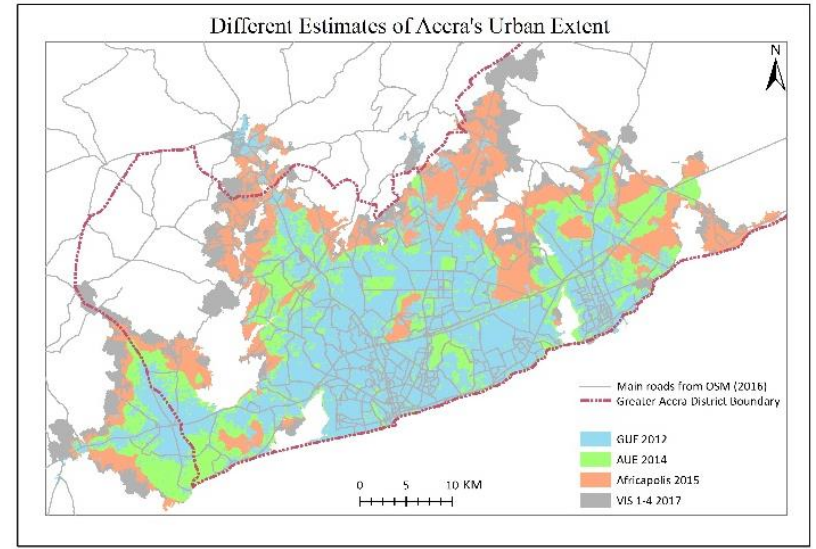

Figure 1. Recent spatial extent of Accra reported by four different studies

Figure 1 shows the agglomeration area reported by four studies within a 5 year period (2012-2017). By selecting the most compatible datasets, and with a focus only on the 'inclusive' methods, an examination of the datasets provides an estimate of the growth rate and current extent of the peri-urban areas. Further, it provides an indication that the spatial growth has slowed down recently from almost $20 \%$ per year in 1991 to ca. $3 \%$ per year in 2017.

\section{DISCUSSION}

In a fast-growing city like Accra mobility forms an integral part of the livelihood strategies. The unplanned spatial expansion of Accra has resulted in limited connectivity both within the city and between it and its hinterlands. Although census data indicate that Accra has 'lost' some of its population to the surrounding districts in recent years, much of the waged employment and job opportunities in the informal economy remain in the city centre.

Daily and regular commuting between central Accra and the municipalities and districts is therefore a regular feature of mobility within the agglomeration, but the public transport system has not developed sufficiently to handle this situation. Situations of extreme urban flooding which seem to have increased in frequency severely affects and hampers mobility by effectively disabling parts of the transport network thereby contributing to the pervasive and exacerbating accessibility problems.

Accurate spatial data on the expansion of the peri-urban areas, as a supplement to the 10 years census data, are necessary to assess the population dynamics of the urban area and to assess the associated mobility and accessibility challenges. This includes modelling the expected "commuter load" on each road segment in Accra under given conditions, providing an indications of the potential impacts of local flooding. By linking this accessibility analysis with local flood risk data obtained from local and city-wide elevation models we expect to be able to produce updated 'vulnerability maps' of the transport network under future climate change-scenarios.

\section{ACKNOWLEDGEMENTS}

Funding for this research was awarded by the Danish Ministry of Foreign Affairs, grant number DFC-17-01-KU.

\section{REFERENCES}

Africapolis, 2019. www.africapolis.org/home Accessed19-3-19. (OECD, Sahel and West Africa Club Secretariat).

Angel, S., Blei, A. M., Parent, J., Lamson-Hall, P \& Sánches, N. G.,2016. Atlas of Urban Expansion 1: Areas and Densities.

DLR, 2019. https://www.dlr.de/eoc/en/desktopdefault.aspx/tabid-9628/16557_read-40454/ Accessed 19-3-19. The German Aerospace Center.

Esch, T., M. Marconcini, M., Felbier, A., Roth, A., Heldens, W., Huber, M., Schwinger, M., Taubenböck, H., Müller, A., \& Dech, S., 2013. Urban Footprint Processor: Fully Automated Processing Chain Generating Settlement Masks From Global Data of the TanDEM-X Mission. IEEE Geoscience And Remote Sensing Letters, 10.

Møller-Jensen, L., R. Y. Kofie \& P. W. K. Yankson, 2005. Large-area urban growth observations: a hierarchical kernel approach based on image texture. Danish Journal of Geography, $105,39-47$.

Revised August 2019 